\title{
Reduction in weed infestation through integrated depletion of the weed seed bank in a rice-wheat cropping system
}

\author{
Zheng Zhang $^{1}$ (D) $\cdot$ Ruhai $\mathrm{Li}^{1,2} \cdot$ Can Zhao ${ }^{1} \cdot$ Sheng Qiang ${ }^{1}$ \\ Accepted: 30 November 2020 / Published online: 11 January 2021 \\ (C) INRAE and Springer-Verlag France SAS, part of Springer Nature 2021
}

\begin{abstract}
Chemical-dependent weed control has led to the evolution of herbicide-resistant weeds and pollution of arable land and water systems, posing a great threat to food security and environmental safety. For the first time, we developed a simple weed management regime to ecologically deplete the weed seed bank under a wheat-rice cropping system, which in turn allowed a reduction in the frequency of conventional herbicide applications while sustainably reducing weed infestation levels. The key ecological methods adopted here involve cleaning irrigation water by intercepting seeds at the water entrance and exit and removing floating weed seeds with a net during irrigation before rice planting, which significantly reduced the input of weed seeds into the seed bank. Quantitative analysis of the weed seed bank and population dynamics showed that implementation of this management regime consecutively for 6 years reduced the density of the total weed seed bank by $51 \%$ and the dominant grassy weed population density by $53 \%$ compared to those at the beginning. The effect of this ecologically sound weed control regime was comparable to that of conventional dual- or triple-application herbicide chemical control in each crop growing season. The results indicated that, compared with the conventional control method, the integrated weed management method could reduce the number of herbicide applications by half and reduce costs and labor by $30 \%$. Furthermore, quantitative modeling analysis of the seed bank and population dynamics of the dominant weed species, Alopecurus japonicus, showed that continuous adoption of this ecological strategy could deplete the seed bank by more than $90 \%$, thereby freeing the fields of the presence of this noxious weed.
\end{abstract}

Keywords Weed communities · Soil seed bank dynamics · Chemical weed control · Ecological management · Integrated weed management $\cdot$ Crop yield $\cdot$ Quantitative analysis

\section{Introduction}

Weed infestations cause considerable losses to agricultural production in terms of both yield and quality (Bastiaans et al. 2008). Although weed control practices are widely adopted during crop cultivation, weed infestations continue to be a constant threat to crop production. This threat is attributed mainly to the existence of the weed seed bank in the soil. The weed seed bank is considered the main source of weed infestations (Chauhan and Johnson 2010). The density and

Sheng Qiang

wrl@njau.edu.cn

1 Weed Research Laboratory, Nanjing Agricultural University, Nanjing 210095, China

2 Institute of Plant Protection and Soil Science, Hubei Academy of Agricultural Sciences, Wuhan, China composition of the weed seed bank directly determine the infestation severity and structure of weed communities in subsequent cropping seasons and impact the efficacy of weed management (Taylor and Hartzler 2000). Exhausting the seed bank is the key to controlling annual weeds and is a major component of integrated weed management (IWM). Numerous measures have been proposed to deplete the seed bank, such as the combination of chemical, agronomic, and ecological controls; however, in practice, effective and sustainable weed management should take the specific situation into consideration. Despite the potential for improving ecological function to support crop production (Pywell et al. 2015), ecological weed management remains relatively understudied and underutilized (MacLaren et al. 2020). Compared with other measures, ecological weed management is oriented more towards long-term management of weed populations rather than acute problem solving. For this reason, long-term monitoring of the evolution of weeds and soil seed bank 
dynamics is critical for evaluating weed management practices for their applicability, efficacy, and sustainability.

Rice (Oryza sativa L.) and wheat (Triticum aestivum L.) are the most important cereal crop species worldwide (Timsina and Connor 2001). Both are part of important double cropping systems for year-round production of more than 26 million $\mathrm{hm}^{2}$ in South and East Asia, contributing immensely to food production (Balasubramanian et al. 2003; Timsina and Connor 2001). Approximately $40 \%$ of this growing area (10.5 million $\mathrm{hm}^{2}$ ) is located in China (Ladha et al. 2003), and the vast majority of this area is located in the Yangtze River valley. Studies have shown that there are 186 weed species distributed in fields of summer crop species (including wheat and rape) and 141 weed species in paddy fields in China (Qiang 2002). Alopecurus species (both Alopecurus aequalis and Alopecurus japonicus) dominate weed communities in association with Beckmannia syzigachne in the summer crop fields, while barnyardgrass (Echinochloa spp.) dominates weed communities in paddy fields (Zhu et al. 2020; Qiang 2005). Uncontrolled weeds can reduce global yields of major crops by approximately $34 \%$ (Oerke 2006). Under the current average weed control level, average yield losses of 15-20\% for rice and $15 \%$ for wheat are caused by weed infestation in China (Zhang 2003). High-efficiency and high-yielding rice and wheat production relies mainly on effective weed management, mostly based on chemical control. Herbicides have become an effective component of weed control: they reduce labor, are profitable, and promote highly efficient tillage and cultivation systems in China, especially in the Yangtze River valley. Five to six herbicide applications are needed during annual cropping cycles. With the excessive use of herbicides, herbicide-resistant weeds and weed population shifts generate new challenges for agriculture. Reduced-herbicide weed management is therefore needed.

Irrigation methods and their frequency have a direct influence on weeds. For the rice-wheat cropping system in the Yangtze River valley, the main irrigation is applied before rice transplanting or direct seeding, which occurs immediately after winter wheat is harvested. Previous work has demonstrated that the seeds of most weed species in paddies and in fields of summer crop species (rape or wheat) can float on the water surface (Li and Qiang 2009); three weed families, Poaceae, Asteraceae, and Polygonaceae, accounted for half of all the weed species identified, suggesting that the seeds of these weeds could readily be dispersed via irrigation water. Seeds of the species whose seeds germinate in the summer accounted for $64 \%$ of the weed seeds collected. Among them, seeds of A. japonicus and B. syzigachne have a high floating density during irrigation and are able to float on water for more than 7 days (Zuo and Qiang 2008). The similarity among weed species dispersed by irrigation water, weed species in communities on the ridge of paddy fields and in the surrounding habitats of ditches, and weed species in successive weed communities in wheat fields and the soil weed seed bank in paddy fields was found to be considerably high (Zhang et al. 2019), suggesting that irrigation water was a major factor affecting the spread of weed seeds and the composition of the soil seed bank.

Propagule dispersal is important for weed population and community dynamics and for the spread of weeds in agroecosystems (Rao et al. 2017). Efforts to reduce weed seed dispersal via irrigation water, particularly in lowland and floodirrigated rice production systems, may be useful in preventing the spread of weed species whose seeds are floatable. Based on the irrigation practices and water seed dispersal in the wheatrice cropping system in the region along the Yangtze River, we proposed two ecological control measures: seed interception from irrigation water and floating weed seed removal, which focused on modifying irrigation water to block seed dispersal. Both of these measures could be components of IWM (integrated weed management). We speculated that the two ecological control measures would ultimately contribute to the reduction in seed rain input and the depletion of the seed bank. However, direct evidence documenting the effectiveness of these measures is still lacking. To evaluate the weed management practices that integrated these weed seed capturing control measures in rice-wheat systems (Fig. 1), we (1) evaluated the soil weed seed bank and weed population dynamics during a 6year period, (2) quantitatively monitored and analyzed the dynamics of the dominant weed A. japonicas within wheat crops, and (3) estimated the change in crop yield with changes in the weed population and seed bank.

\section{Materials and methods}

\subsection{Study site}

The experiment was conducted at Xiangyang farm, Jiangyin city, Jiangsu Province, China, which is located in the subtropical monsoonal zone, from 2006 to 2012. The mean annual temperature at the location varies from 15 to $16^{\circ} \mathrm{C}$, and the mean annual rainfall varies from 1000 to $1100 \mathrm{~mm}$, approximately $50 \%$ of which occurs from June to September. The soil at the site is a yellow-brown soil with the following nutrient contents: total nitrogen, $2.18 \mathrm{~g} \mathrm{~kg}^{-1}$; total phosphorus, $0.64 \mathrm{~g} \mathrm{~kg}^{-1}$; total potassium, $14.75 \mathrm{~g} \mathrm{~kg}^{-1}$; and organic matter, $23.4 \mathrm{~g} \mathrm{~kg}^{-1}$. The $\mathrm{pH}$ of the tilled layer was 6.7. Before the study, the experimental site had been under a typical rice (summer-autumn)-wheat (winterspring) double cropping system for more than 20 years.

\subsection{Weed and crop management}

Twelve adjacent fields separated by concrete ridges, each of which was approximately $500 \mathrm{~m}^{2}$, were selected as experimental plots. Four different weed management tactics, 
Fig. 1 The implementation of ecological control measures-seed interception and floating weed seed removal in wheat-rice cropping system.

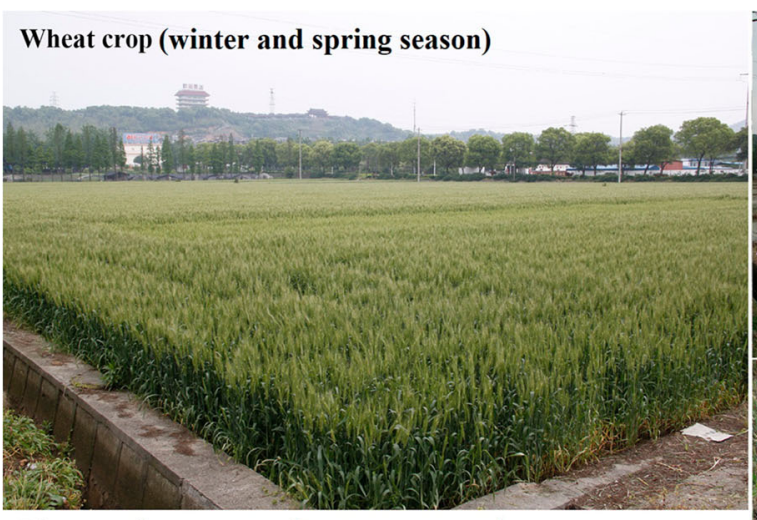

Rice crop (summer and autumn season)

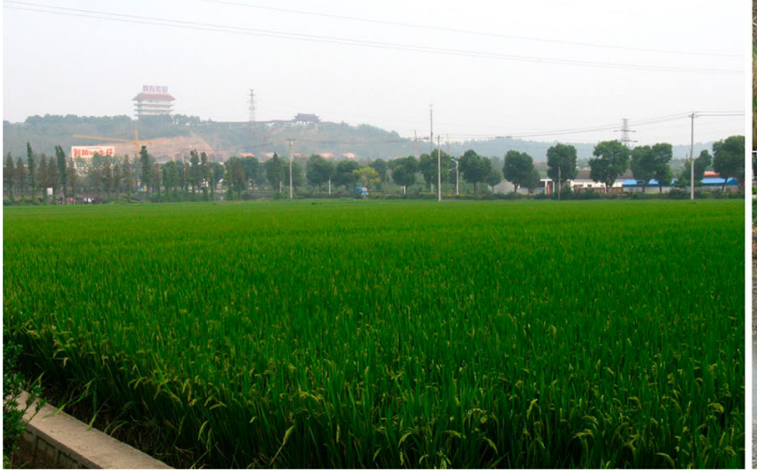

designated $\mathrm{CH} 0, \mathrm{CH} 1, \mathrm{NG}$, and $\mathrm{CH} 2$, were applied in accordance with a completely random design with three replications (see Table 1 for a concise comparison of the four management tactics). Conventional chemical control was applied in all the treatments $(\mathrm{CH} 0, \mathrm{CH} 1, \mathrm{NG}, \mathrm{CH} 2)$ : once during the rice season $(50 \%$ mefenacet $+3 \%$ bensulfuron-methyl wettable powder (WP), at $445 \mathrm{~g}^{\text {ai } \mathrm{hm}^{-2}}$ ) at 7 days after rice transplanting and twice in wheat fields (50\% isoproturon WP, at $900 \mathrm{~g}$ ai $\mathrm{hm}^{-2}$, applied 25 days after wheat sowing; $6.9 \%$ fenoxapropp-ethyl suspoemulsion (SE), at $750 \mathrm{ml} \mathrm{hm}^{-2}$, applied in March). An additional herbicide application was applied in the $\mathrm{CH} 2$ treatment: $10 \%$ flucetosulfuron WP in the rice field at a rate of $30 \mathrm{~g}$ ai hm$^{-2}$ applied at the 2-5-leaf stage, and $15 \%$ clodinafop-propargyl WP in the wheat field at a rate of $22.5 \mathrm{~g}$ ai $\mathrm{hm}^{-2}$ applied at the 3-5-leaf stage. The seed interception measures were applied in treatments $\mathrm{CH} 1, \mathrm{NG}$, and $\mathrm{CH} 2$ : filters $(50 \mathrm{~cm} \times 60 \mathrm{~cm})$ constructed of stainless steel frames, and bistratal nylon nets $(0.125-\mathrm{mm}$ mesh) were placed at the field water entrance and exit in treatments $\mathrm{CH} 1, \mathrm{NG}$, and $\mathrm{CH} 2$ to stop weed seeds from entering or leaving the experimental plots via irrigation water. The floating seed removal measure was applied in NG treatment: the floating weed seeds were collected before rice transplanting with a fishing tuck net from the flooded field after harrowing but before rice transplanting.

In treatments $\mathrm{CH} 1, \mathrm{CH} 2$, and $\mathrm{NG}$, the filters were checked daily, and the intercepted weed seeds were collected and removed.

Each year after wheat harvest, the remaining wheat straw was ploughed into the soil and allowed to decompose for 10 days so that it could nourish the rice seedlings. Rice (cultivar Wuyujing) seedlings were transplanted mechanically at a spacing of $15 \mathrm{~cm} \times 30 \mathrm{~cm}$, with 3 seedlings hill ${ }^{-1}$. After rice harvest, wheat (cultivar Yangmai 158) seeds were broadcast into the field (without tillage) at a seeding rate of $150 \mathrm{~kg} \mathrm{hm}^{-2}$.

Tillage was performed only once a year during the field preparation period for rice transplanting after wheat harvest.
Table 1 Weed management tactics evaluated for their impact on the soil seed bank

\begin{tabular}{|c|c|c|c|c|}
\hline \multirow[t]{2}{*}{ Treatments } & \multicolumn{2}{|c|}{ Chemical weed control } & \multirow[t]{2}{*}{ Seed interception } & \multirow[t]{2}{*}{ Other weed control methods } \\
\hline & Wheat season & Rice season & & \\
\hline $\mathrm{CHO}$ & Twice & Once & None & None \\
\hline $\mathrm{CH} 1$ & Twice & Once & Yes & None \\
\hline NG & Twice & Once & Yes & Floating seed removal by a tuck net \\
\hline $\mathrm{CH} 2$ & Thrice & Twice & Yes & None \\
\hline
\end{tabular}


During the rice cropping season, fertilizer was applied four times: once as a basal fertilizer, which involved $5.4 \mathrm{~kg} 667 \mathrm{~m}^{-2}$ urea, $6 \mathrm{~kg} 667 \mathrm{~m}^{-2}$ superphosphate $\left(\mathrm{P}_{2} \mathrm{O}_{5}\right)$, and $4 \mathrm{~kg} 667 \mathrm{~m}^{-2}$ $\mathrm{KCl}\left(\mathrm{K}_{2} \mathrm{O}\right)$ applied before tillage; once as a tillering fertilizer, which involved urea applied at $15 \mathrm{~kg} 667 \mathrm{~m}^{-2}$ at 7 days after transplanting; twice as a panicle fertilizer, which involved $10 \mathrm{~kg} 667 \mathrm{~m}^{-2}$ urea and $4 \mathrm{~kg} 667 \mathrm{~m}^{-2} \mathrm{KCl}\left(\mathrm{K}_{2} \mathrm{O}\right)$ applied at the last 4-leaf stage; and $6 \mathrm{~kg} 667 \mathrm{~m}^{-2}$ urea applied at the last 2leaf stage.

During the wheat cropping season, fertilizer was applied three times: once as basal fertilizer, which involved $5 \mathrm{~kg}$ $667 \mathrm{~m}^{-2}$ urea, $9 \mathrm{~kg} 667 \mathrm{~m}^{-2}$ superphosphate $\left(\mathrm{P}_{2} \mathrm{O}_{5}\right)$ and $9 \mathrm{~kg}$ $667 \mathrm{~m}^{-2} \mathrm{KCl}\left(\mathrm{K}_{2} \mathrm{O}\right)$ applied before sowing; once as a seedling fertilizer, which involved $7.5 \mathrm{~kg} 667 \mathrm{~m}^{-2}$ urea applied after seedling establishment; and once as a panicle fertilizer, which involved $10 \mathrm{~kg} 667 \mathrm{~m}^{-2}$ urea applied at the last 3-leaf stage.

\subsection{Analysis of the captured weed seeds in NG treatment}

In the NG treatment, the seeds gathered by the use of a tuck net from the same field were pooled as a sample. All the collected seed samples were weighed, and then, 1/40th of each sample was placed in properly labelled plastic bags, which were then brought to the laboratory. Each sample that was brought back was transferred to a bag made of nylon mesh (pore diameter of $0.1 \mathrm{~mm}$ ) and washed with tap water to remove the soil. The residue containing the weed seeds was airdried, and the subsamples, weighing 1/20th of gross weight of each air-dried sample (1/800th of the whole sample), were sieved through increasingly finer meshes (20-, 40-, 60-, 80-, 100-, 120-, and 150-mesh sizes). The residue from each sifting was placed into Petri dishes and examined under a binocular microscope (maximum magnification of $\times 400$ ) to quantify the amount and species of weed seeds. The number of collected seeds in each plot was expressed as the number of seeds per square meter according to the sample weight and plot area.

\subsection{Seed bank sampling}

From 2006 to 2012, each year after rice (late October, autumn seed bank) and wheat harvest (early June, spring seed bank), soil samples were collected manually from each field plot. The weed seed bank base of the spring seed bank was investigated after the wheat harvest in 2006. Each sampling included ninety soil cores ( $25 \mathrm{~mm}$ in diameter, $15 \mathrm{~cm}$ in depth) taken from each plot using parallel grids; these grids divided each plot into thirty subsections with 3 rows to systematically distribute the sampling locations. Each core was split into three subcores along its length: an upper layer $(0-5 \mathrm{~cm})$, a middle layer $(5-10$ $\mathrm{cm})$, and a bottom layer $(10-15 \mathrm{~cm})$. Soil from the same layer of each plot was pooled and mixed thoroughly to form composite samples. The soil samples were subsequently air-dried and pulverized. Three subsamples were taken from each of the three layers, with each subsample weighing 1/10th of the gross weight of the whole sample. Each subsample was put into a small bag made of nylon mesh (pore diameter of 0.1 $\mathrm{mm}$ ) and washed with tap water to remove the soil.

The residue containing the weed seeds was air-dried and sieved through increasingly finer meshes $(20-, 40-, 60-, 80-$, 100-, 120-, and 150-mesh sizes). The residue from each sifting was placed into Petri dishes and examined under a binocular microscope (maximum magnification of $\times 400$ ) for weed seed identification.

The weed seeds were identified according to illustrated handbooks (Guan et al. 2000). Viable seeds were assessed through slight pressure from fingers (Vasileiadis et al. 2007). The total number of viable seeds in each subsample was determined, and seed density was expressed as the number of seeds per square meter based on the surface area of the cores and the weight of the whole sample.

\subsection{Above-ground weed investigation}

Weed density was surveyed 4 times each year from 2006 to 2012, twice in each crop. Weed seedlings were surveyed 30 days after rice transplanting (usually during the last 10 days of July, after the soil-applied herbicide application) and 20 days after wheat sowing (usually in mid-November, before the second herbicide application). Mature weeds were sampled in early October in the rice fields and in late May in the wheat fields. For the assessment, five square quadrats, each measuring $0.25 \mathrm{~m}^{2}$, were randomly placed in each plot, and the species and quantity of weeds in each quadrat were carefully examined. The crop density was also measured. Moreover, 50 rice or wheat plants per treatment were selected at maturity during the weed density survey to determine the tiller number, seed number per panicle, seed setting rate, and 1000-grain weight.

\subsection{Data analysis}

All statistical analyses were performed with SPSS 22 (IBM Corporation, Armonk, NY, USA), and all figures were constructed using OriginPro 2019b (OriginLab Corporation, Northampton, MA, USA).

The theoretical crop yield $\left(\mathrm{kg} \mathrm{hm}^{-2}\right)\left(M_{\mathrm{c}}\right)$ was calculated according to the data collected from field investigations according to the equation shown below:

$M_{\mathrm{c}}=D_{\mathrm{c}} \times N_{\mathrm{t}} \times N_{\mathrm{s}} \times S_{\mathrm{r}} \times W \times 10^{-2}$

where $D_{\mathrm{c}}$ is the rice/wheat density (individuals $\mathrm{m}^{-2}$ ), $N_{\mathrm{t}}$ is the tiller number per plant, $N_{\mathrm{s}}$ is the seed number per panicle, $S_{\mathrm{r}}$ is the seed setting rate, and $W$ is the 1000 -grain weight (g). 
The data were tested for homogeneity (Levene's test) first, after which analysis of variance (ANOVA) was used to distinguish the influence of different weed management practices on the density of the weed seed bank, density of the above-ground weed population, and crop yield.

Matrix modeling was used to understand how the ecological weed control measures (seed interception and net gain of floating seeds) affect the demographics of the dominant weed species A. japonicas in wheat fields and what population nodes these measures affect. The characteristic population endpoints (such as the reproductive value, germination rate, seedling survival rate) are summarized in Fig. 6a.

Seven demographic parameters of A. japonicas were estimated using data obtained from the field investigations of the Jiangyin experiment from 2006 to 2012 such that the matrix model for A. japonicas was parameterized using the following whole-life cycle data sets:

$g$ : plant recruitment (seed germination rate)

$\beta_{\mathrm{w}}$ : seed survival rate from November to July in the seed bank

$\mu$ : plant survival rate after chemical herbicide application

$f$ : seed production per plant (plant fecundity)

$\eta$ : proportion of seeds that shattered onto the soil surface prior to irrigation

$\alpha$ : depletion of newly shattered seeds at irrigation

$\beta_{\mathrm{s}}$ : seed survival rate from July to October through the seed bank

We simulated the effects of seed interception and removal on the A. japonicas population growth rate using periodicmatrix population models (Davis et al. 2004), which explicitly account for variations in transition probabilities within a sequence of the whole life cycle. The model followed A. japonicas demographics through four subannual periods in one rotation cycle. We did not define a depth-structured seed bank.

The four subannual projection matrices are as follows:

Recruitment:

$B_{1}=\left[\begin{array}{cc}1-g & 0 \\ 0 & 0\end{array}\right]$

Winter survival:

$B_{2}=\left[\begin{array}{cc}\beta_{w} & 0 \\ 0 & \mu\end{array}\right]$

Fecundity:

$B_{3}=\left[\begin{array}{cc}1 & f \eta \alpha \\ 0 & 0\end{array}\right]$
Survival number:

$B_{4}=\left[\begin{array}{cc}\beta_{s} & 0 \\ 0 & 0\end{array}\right]$

The matrix models followed the general form shown here:

$$
\begin{aligned}
& n_{t+1}=[B 1 \ldots B k] n t \quad k=4 \quad[1] \\
& =A n t
\end{aligned}
$$

where $n$ is a vector of the population size, with $i$ rows representing the number of individuals in each life stage $i$ at time $t$ and $t+1, B$ is a projection matrix for period $h$, and $A$ represents the annual projection matrix for the entire life cycle, with $i$ rows and $j$ columns containing all life stage transition probabilities for the weed species being modeled.

Because only the dormant seeds of A. japonicas within the soil seed bank survive during the summer and autumn, the projection over the entire rotation cycle starting in the summer describes changes in the number of seeds over time, with only one nonzero element, $\mathrm{a}_{11}$, in $A$. In terms of the parameters of $\mathrm{a}_{11}$ describing the important events in the life cycle, the matrix is simplified to the following function:

$\mathrm{a}_{11}=\beta_{s} \times g \times \mu \times f \times \eta \times(1-\alpha)+\beta_{\mathrm{s}} \times \beta_{\mathrm{w}} \times(1-g)$

The first string of parameters in $\mathrm{a}_{11}, \beta_{\mathrm{s}} \times e \mu \times e \eta \times \alpha$, describes the above-ground pathway for the annual life cycle, in which seeds germinate, seedlings survive to reproductive maturity, new seeds shatter, and seeds enter the seed bank. The second string of parameters in $\mathrm{a}_{11}, \beta_{\mathrm{s}} \times \beta_{\mathrm{w}} \times(1-g)$, describes the belowground pathway for the annual life cycle, in which seeds remain dormant and survive until the following growing season. Because $\beta_{\mathrm{s}}$ appears in both the above- and belowground pathways, changes in this parameter are directly proportional to changes in population growth rate $\lambda$, making it a bottleneck in the life cycle of annual weeds.

The seedling germination rate and plant fecundity were density dependent, and the density-dependent parameters were $\sigma_{\mathrm{g}}$ and $\sigma_{\mathrm{f}}$.

\section{Results and discussions}

\subsection{Influence of weed management practices on the soil seed bank density and composition}

Grassy weeds constituted 25.7 to $30.2 \%$ of the soil seed bank at the onset of the study, both in the autumn and spring, while broadleaf weeds constituted 64.4 to $71.0 \%$ of the soil seed bank, and sedges constituted 3.3 to $6.0 \%$. Though the seed bank density of overall weeds, grassy weeds, and broadleaf weeds varied under the different treatments, there was no significant difference between the treatments at the beginning. 
With the implementation of different weed management practices during the study years, differences between treatments appeared. All the variation trends of weed seed density under the four treatments conformed to the exponential decay models (adjusted $R^{2}>0.9$ ) (Fig. 2a, b).

Density of spring weed seed bank (seeds $\mathrm{m}^{-2}$ )
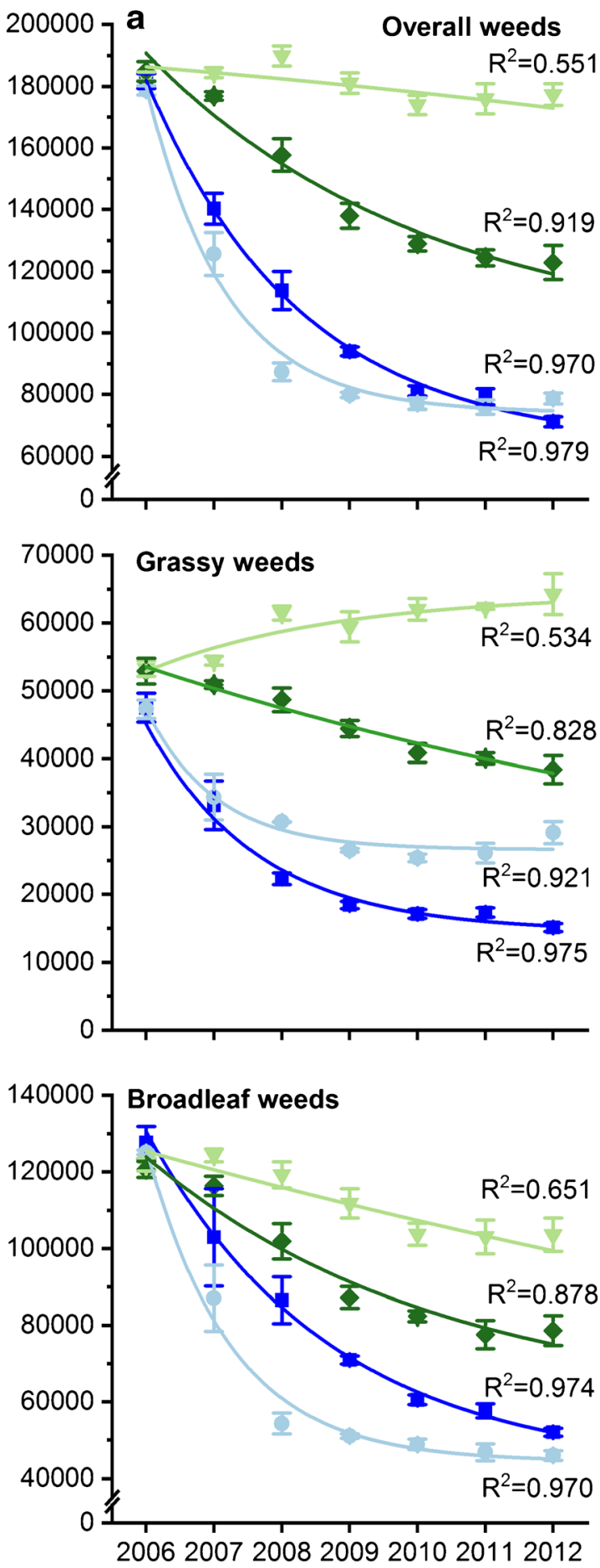

Except under $\mathrm{CH} 0$ treatment, the total seed bank density decreased significantly throughout the experiment period, and the extent of the decrease varied across treatments. At the end of the 6-year experimental period, the greatest decrease happened under NG treatment, which reduced the total seed bank

Density of autumn weed seed bank (seeds $\mathbf{m}^{-2}$ )
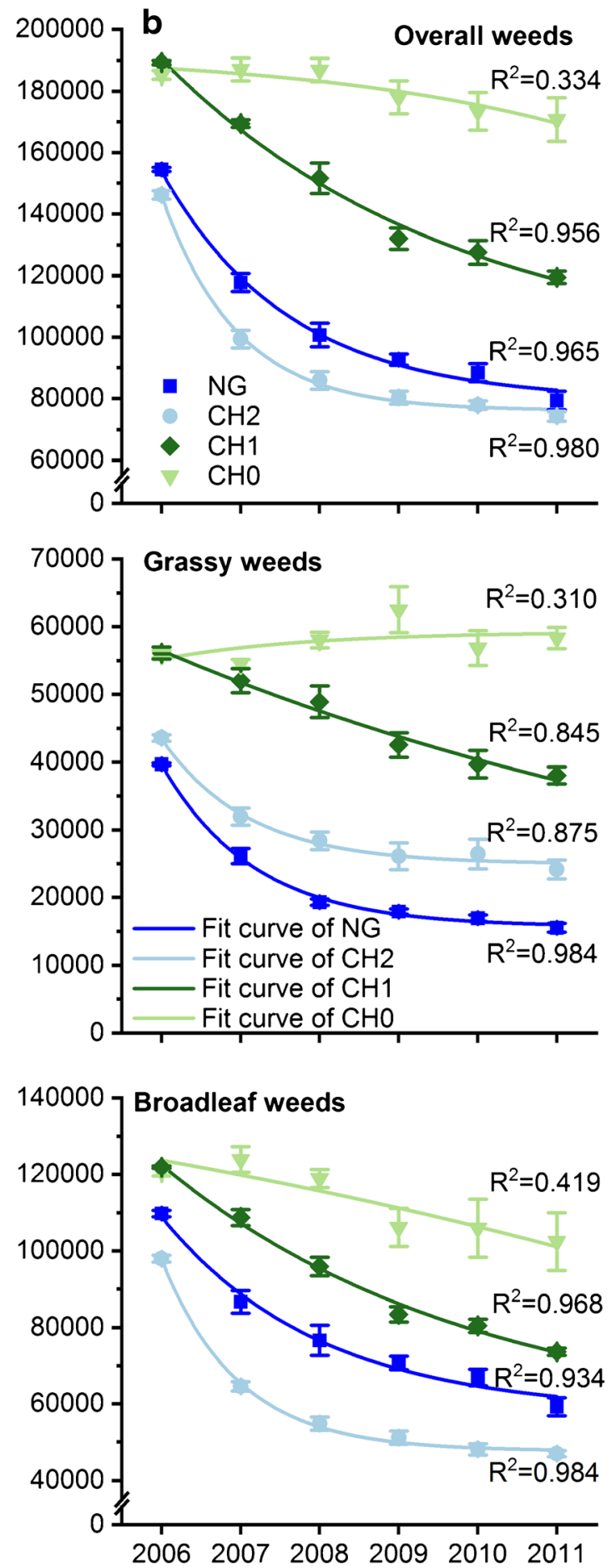

Fig. 2 Regression analysis of the dynamics of the spring (a) and autumn (b) seed bank density under four different treatments from 2006 to 2012 . The error bars indicate the means \pm SEs. 
to approximately $39.2 \%$ of the initial density (from 181689 to 71244 seeds $\mathrm{m}^{-2}$ ) in the spring and to $51.4 \%$ of the initial density (from 154498 to 79378 seeds $\mathrm{m}^{-2}$ ) in autumn (Fig. $2 \mathrm{a}, \mathrm{b})$. With respect to the grassy weed seed bank, the greatest decrease in density was consistently observed in the plot subjected to seed entry interception and floating weed seed removal with a net under the NG treatment, which resulted in a $68.2 \%$ reduction in the spring and a $60.9 \%$ reduction in autumn at the end of the 6-year period. In contrast, the density of the grassy weed seed bank increased by $20.6 \%$ in the spring and by $4.2 \%$ in autumn under $\mathrm{CH} 0$ treatment, which occurred in the absence of both seed interception and removal measures from irrigation water. With respect to broadleaf weeds, the seed bank density under all four treatments decreased, and the decreases (in ascending order) were $15.0 \%, 34.9 \%, 59.2 \%$, and $63.3 \%$ in the spring and $15.2 \%, 39.6 \%, 46.0 \%$, and $52.0 \%$ in autumn for $\mathrm{CH} 0, \mathrm{CH} 1, \mathrm{NG}$, and $\mathrm{CH} 2$, respectively.

The seed bank density was significantly lower under $\mathrm{CH} 1$ treatment than under $\mathrm{CH} 0$ treatment. This indicated that seed interception from irrigation water had a significantly positive effect on the depletion of the weed seed bank. This was especially important for grassy weeds, whose seed bank substantially increased during the experimental period in the absence of any water floating seed removal. By comparing treatments $\mathrm{NG}, \mathrm{CH} 2$, and $\mathrm{CH} 1$, we found significant differences in the grassy weed seed bank density and broadleaf weed seed bank density $(p<0.05)$. The density of the grassy weed seed bank was in the order of $\mathrm{CH} 1>\mathrm{CH} 2>\mathrm{NG}$, while the order of the broadleaf weed seed bank density was $\mathrm{CH} 1>\mathrm{NG}>\mathrm{CH} 2$, which indicated that the number of herbicide applications $(\mathrm{CH} 2)$ or the addition of weed seed removal practice (NG) had positive effects on seed bank depletion, but the effects were different between grassy weeds and broadleaf weeds. Floating seed removal was more effective at reducing grassy weeds, while the application of herbicide was more effective at reducing broadleaf weeds.

Under the NG treatment, the floating weed seeds were captured by a tuck net before rice planting. The highest captured seed density reached approximately 6500 seeds $\mathrm{m}^{-2}$ in 2007 in the second year of the experiment but decreased to approximately 3000 seeds $\mathrm{m}^{-2}$ in the seventh year (2012) (Fig. 3). The weeds seeds in wheat constituted the majority (88.3-90.6\%) of the total captured seeds, while the weed seeds in rice constituted the remaining 9.4-11.7\%. Among all the directly retrieved weed seeds, $88-92 \%$ were seeds of grassy weed species, approximately $98 \%$ were from wheat fields, and the most abundant seeds were from A. japonicas and B. syzigachne. During our investigation, the seed rain was approximately 25,000 seeds $\mathrm{m}^{-2}$ in 2006 , but it decreased by more than half to approximately 10,000 seeds $\mathrm{m}^{-2}$ in 2011 . Approximately $20-40 \%$ of the newly produced seeds were captured by the tuck net, which resulted in the obvious decline in seed bank input from seed rain.
Weed seed bank dynamics are affected mainly by input and output factors (Buhler et al. 1997). Sources of input include seed rain (Webster et al. 2003), irrigation water (Zuo and Qiang 2008; Qiang 2005), wind (Dauer et al. 2007), animals (Reader 1991), and farming activity related to cultivation. The main mechanisms of output include germination and death, as well as predation (Westerman et al. 2008; Baraibar et al. 2009). If the output is larger than the input, the size of the weed seed bank gradually declines, the weed seedlings decreases, and the weed population eventually becomes effectively controlled. Weed seeds falling to the ground (seed rain) are an important supplement to the soil seed bank. Seeds create a potential control point in the weed life cycle that is fundamentally different than the stages currently targeted by most management practices (Haring and Flessner 2018). Chemical herbicides can reduce the weed population density directly during the weed growth period, further resulting in the indirect reduction in weed seed production (seed rain). The weed population density could be further reduced with additional chemical weed control ( $\mathrm{CH} 2$ treatment); consequently, it may be beneficial to reduce the seed input of the seed bank from seed rain if herbicide resistance does not evolve. Based on the seed dispersal method and seed floating characteristics (Zhang et al. 2019; Zuo and Qiang 2008) in rice-wheat cropping systems, water-cleaning measures can significantly directly reduce seed input through the interception and capture of floating seeds at the water entrance and in the field.

When the ecological measures of seed interception (placing a net filter at the water entrance and exit; $\mathrm{CH} 1, \mathrm{CH} 2$, and $\mathrm{NG}$ treatments) and floating weed seed removal (NG treatment) were added to the single herbicide-application treatment (CH0), the soil seed bank depletion accelerated. The two measures were aimed at reducing the amount of seed input into the seed bank. Irrigation water is an important dispersal agent for weed seeds in wheat-rice double cropping fields in the Yangtze River region (Li and Qiang 2009; Zuo and Qiang 2008). The seed interception measure could intercept the weed seed input and output though the irrigation water, which reduced the input amount of weed seeds that entered the soil seed bank and that originated from seed rain produced by neighboring fields, by an average of 1000-5000 seeds $\mathrm{m}^{-2}$ year $^{-1}$. Floating seed removal reduced a large input amount of newly produced weed seeds just in the field, by an average of 3000-6500 seeds $\mathrm{m}^{-2}$ every year. Given the strong buoyancy of grassy weeds, the floating seed removal measure was much more effective for grassy weed seeds than for broadleaf weed seeds.

\subsection{Influence of weed management practices on weed populations}

Grasses dominated the weed communities in the wheat crop, accounting for more than $90 \%$ of the total weed population 


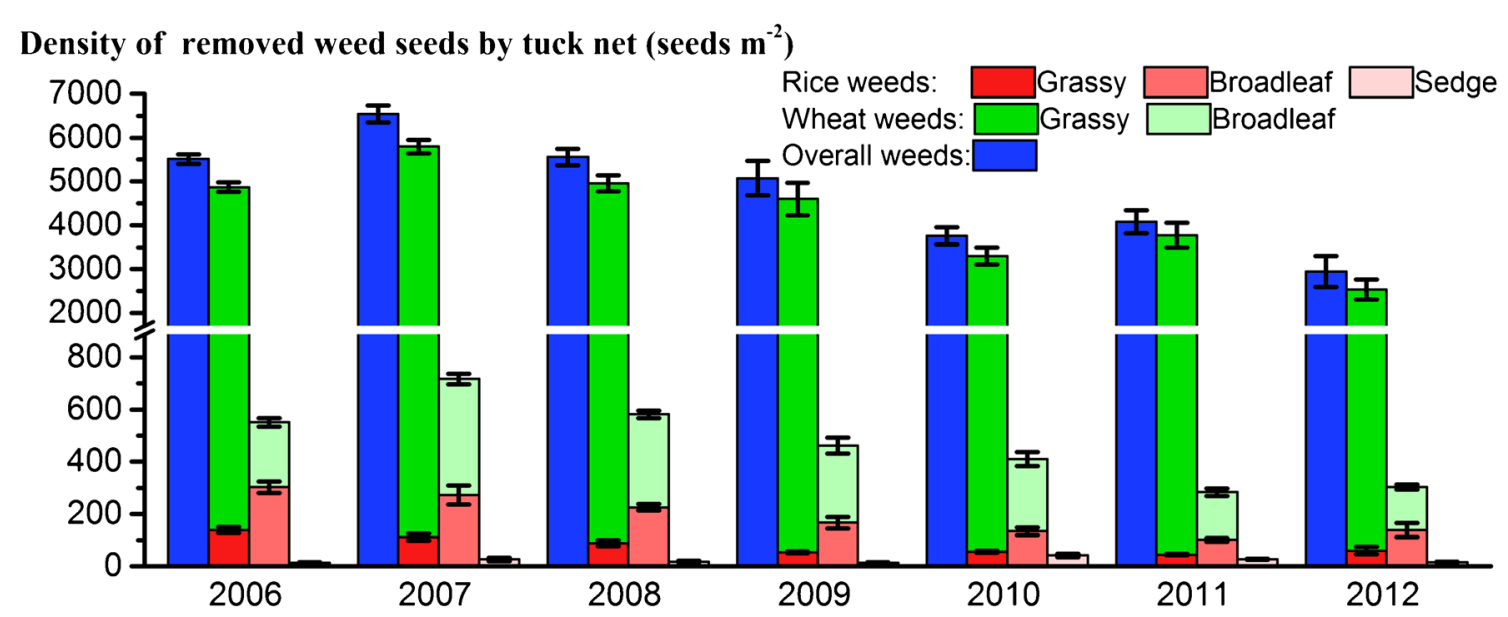

Fig. 3 Composition of weed seeds removed by a tuck net under treatment NG. The error bars indicate the means \pm SEs.

(Fig. 4). Among them, A. japonicas and B. syzigachne were the two most abundant species, accounting for more than $90 \%$ of the total grassy weed population in wheat. Broadleaf weeds dominated the weed communities in the rice crop, accounting for approximately $60 \%$ of the total weed population (Fig. 4). Among them, Monochoria vaginalis and Lindernia procumbens were the most abundant species, accounting for $65-85 \%$ of the total broadleaf weeds in rice.

Seedling recruitment and adult weed plants in both wheat and rice crops were impacted by weed management practices. Except in CH0 treatment, the recruited seedlings and adults of grassy weeds, broadleaf weeds, and total weeds in wheat declined annually under the treatments ( $\mathrm{NG}, \mathrm{CH} 2$, and $\mathrm{CH} 1)$. At the end of the 6-year experimental period, with respect to seedling recruitment, the greatest decreases recorded were $54.7 \%$ for grassy weeds and $53.1 \%$ for total weeds under the NG treatment in wheat, while the greatest decrease in broadleaf weeds was recorded under the $\mathrm{CH} 2$ treatment. Moreover, the decrease in the adult weeds in wheat was the highest under NG treatment - approximately $59.6 \%$ for total weeds, $57.9 \%$ for grassy weeds, and $40.0 \%$ for broadleaf weeds - at the end of the experiment. The results indicated that seed interception (CH1, NG, and $\mathrm{CH} 2$ ), floating seed removal (NG), and the addition of two herbicide applications $(\mathrm{CH} 2)$ promoted the control of weed seedling recruitment and adult weeds. When treatments $\mathrm{NG}$ with $\mathrm{CH} 2$ are compared, the removal of floating seeds after wheat harvest is more effective than the increase in herbicide use for controlling weeds in wheat, especially for grassy weeds over a long treatment period.

In rice, during the 6-year experiment, the adult plants of total weeds decreased gradually each year under all four treatments with decreasing extents (CH0 (10.8\%), CH1 (40.7\%), NG (54.7\%), and CH2 (63.8\%)), and the same downward trend occurred for the broadleaf weeds. However, under $\mathrm{CH} 0$ treatment, the density of adult grassy weeds increased by $28.7 \%$ at the end of the experiment, and the proportion of grassy weeds among the total weeds increased significantly.
These results indicated that the single herbicide application in rice did not control grassy weeds effectively, but the addition of a second herbicide application ( $\mathrm{CH} 2)$, the addition of ecological methods involving water interception $(\mathrm{CH} 1, \mathrm{NG}$, $\mathrm{CH} 2$ ), and the removal of floating weed seeds (NG) before rice planting were effective at controlling weeds in rice fields.

Long-term sustainable and effective weed control depends on maintaining a depleted seed bank. The weed seed bank is the main source of weed infestation in agricultural fields (Fulekar et al. 2013). Thus, the seed bank reflects the longterm effects of weed management practices on above-ground vegetation. The present study showed that both $\mathrm{NG}$ and $\mathrm{CH} 2$ were effective at controlling the weed seed bank and weed populations. The overall control efficiency under NG and $\mathrm{CH} 2$ was similar after treatment had occurred for several years (5-6 years). However, weeds are more likely to evolve resistance to herbicides where herbicide use is more intense (Hicks et al. 2018). For the $\mathrm{CH} 2$ treatment ( 2 herbicide applications in rice and 3 applications in wheat), excessive chemical weed control could increase the environmental risk as well as the risk of herbicide resistance in weeds. Compared with the $\mathrm{CH} 2$ treatment, the NG treatment, in which the number of herbicide applications is reduced ( 1 application in rice and 2 applications in wheat) and which is integrated with ecological measures, could reduce the amount of herbicide used, which is beneficial for farmland environments and still resulted in satisfactory control effects. Therefore, compared with the $\mathrm{CH} 2$ treatment, the NG treatment is much more recommended from an ecological standpoint. Furthermore, with the floating seed removal, which is the main element of the NG treatment, operability determines its actual application. In the middle and lower reaches of the Yangtze River, the monsoon is prevalent during the rice planting season. Based on our observations, the monsoon plays an active role in the gathering of floating weed seeds in ridges and corners of fields because of wind (Zhang et al. 2019), which could make floating seed removal by nets relatively easy. In this case, the NG treatment, 
Densities of weed seedlings in rice (individuals $\mathrm{m}^{-2}$ )

a
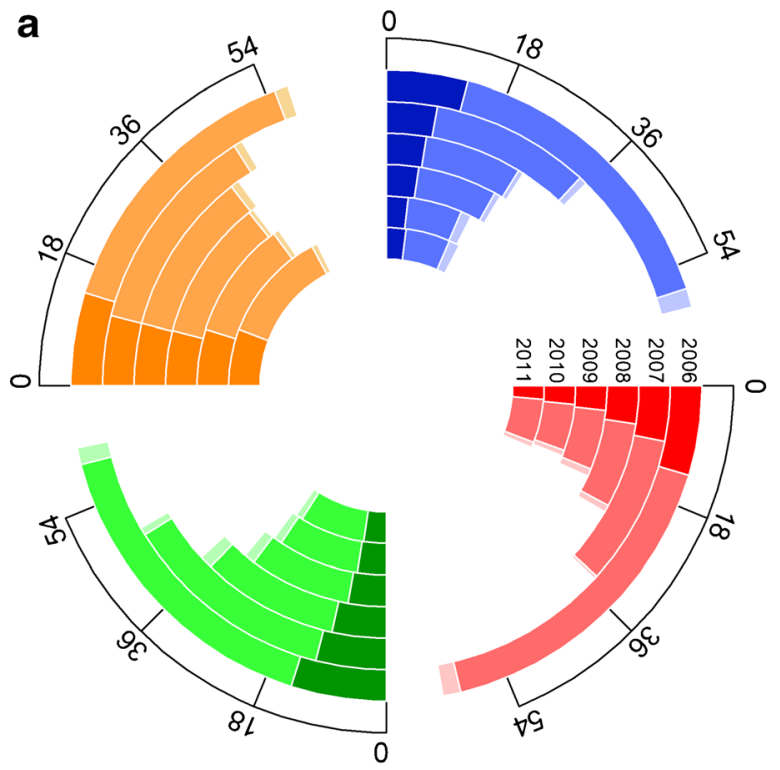

\section{Densities of weed seedlings in wheat (seedlings $\mathrm{m}^{-2}$ )}

c
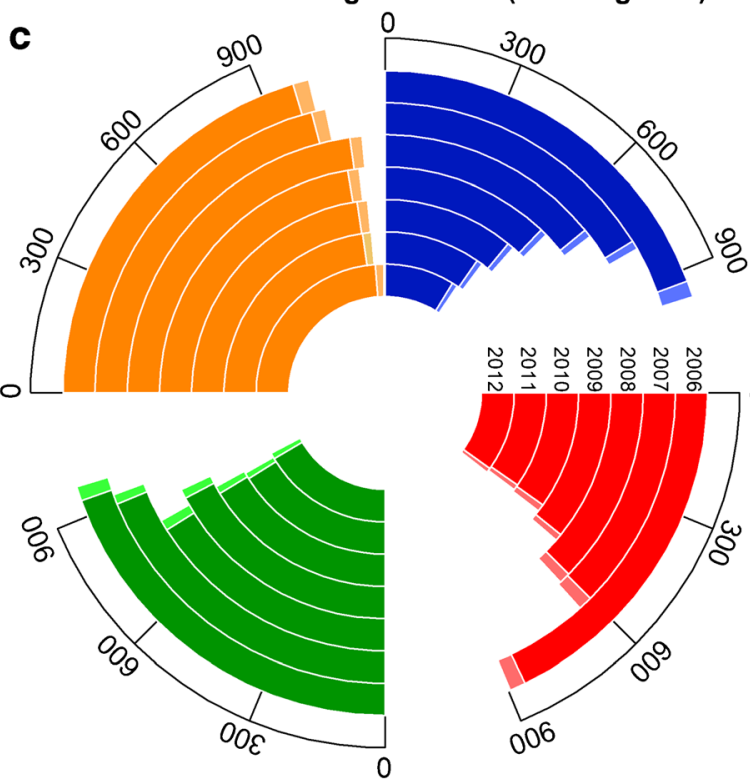

Densities of adult weed populations in rice (individuals $\mathrm{m}^{-2}$ )

b
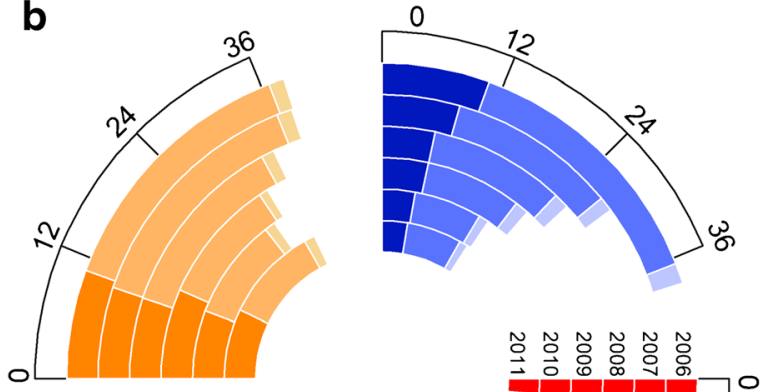

NG

GR

$B L$

SE

$\mathrm{CH} 2$

GR

$B L$

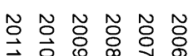
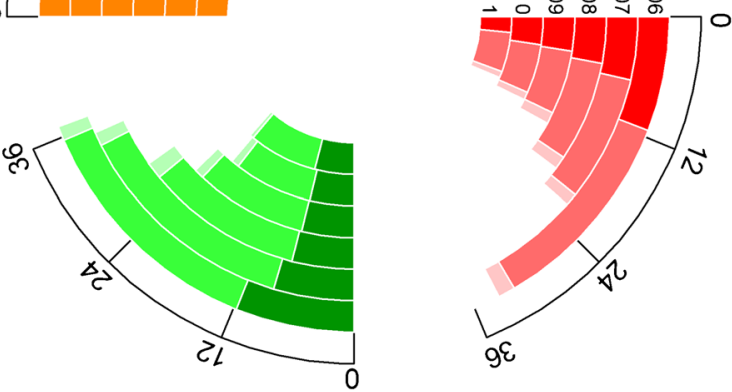

$\mathrm{CH} 1$

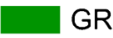

BL

SE

$\mathrm{CHO}$

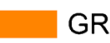

$B L$

SE

Densities of adult weed populations in wheat (individuals $\mathbf{~}^{-2}$ )

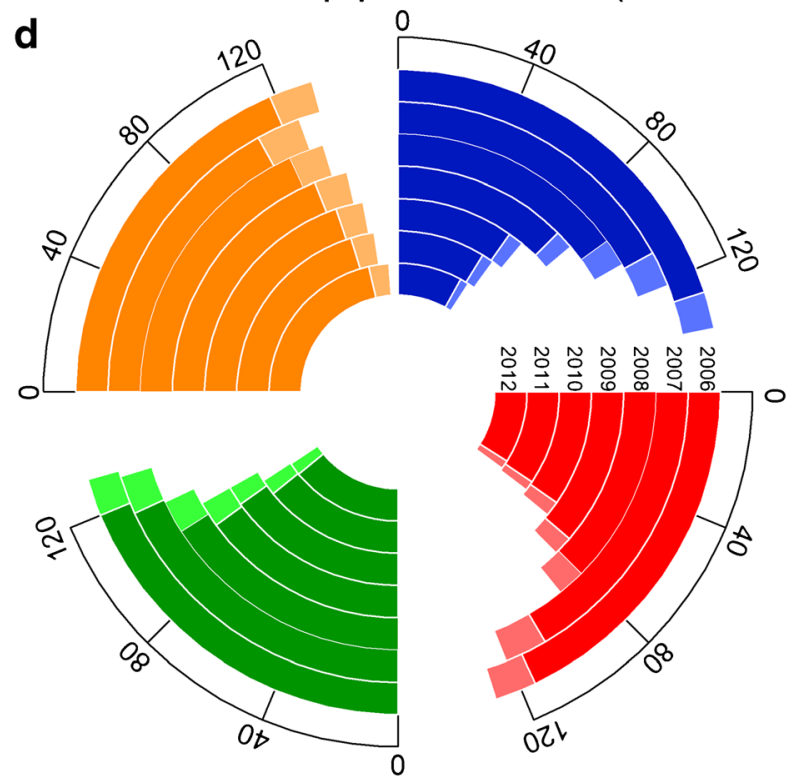

Fig. 4 Influence of different weed management practices on seedling recruitment and adult plant populations in rice (a and b) and wheat crops (c and d). GR: grassy weeds; BL: broadleaf weeds; SE: sedge weeds.

which involves removing weed seeds via nets, may be feasible.

\subsection{Influence of weed management practices on crop yields}

The difference in the rice and wheat yields between the four treatments increased with increasing time (Fig. 5). Initially, there was no significant difference between the four treatments. However, after 6 years, there were increases of $4.9 \%$ and $2.5 \%$ for wheat and rice yields, respectively, under NG treatment and increases of $4.0 \%$ and $3.7 \%$ for wheat and rice yields, respectively, under $\mathrm{CH} 2$ treatment. The wheat yields under $\mathrm{CH} 2$ and $\mathrm{NG}$ treatments and the rice yields under $\mathrm{CH} 2$ treatment were significantly higher than those under $\mathrm{CHO}$ and $\mathrm{CH} 1$ treatments, but the difference in wheat and rice yields between $\mathrm{NG}$ and $\mathrm{CH} 2$ was not significant. The lowest wheat yield and rice yield occurred under $\mathrm{CH} 0$ treatment, with decreases of $4.6 \%$ and $3.8 \%$, respectively, compared with the yields at the beginning of the experiment. 

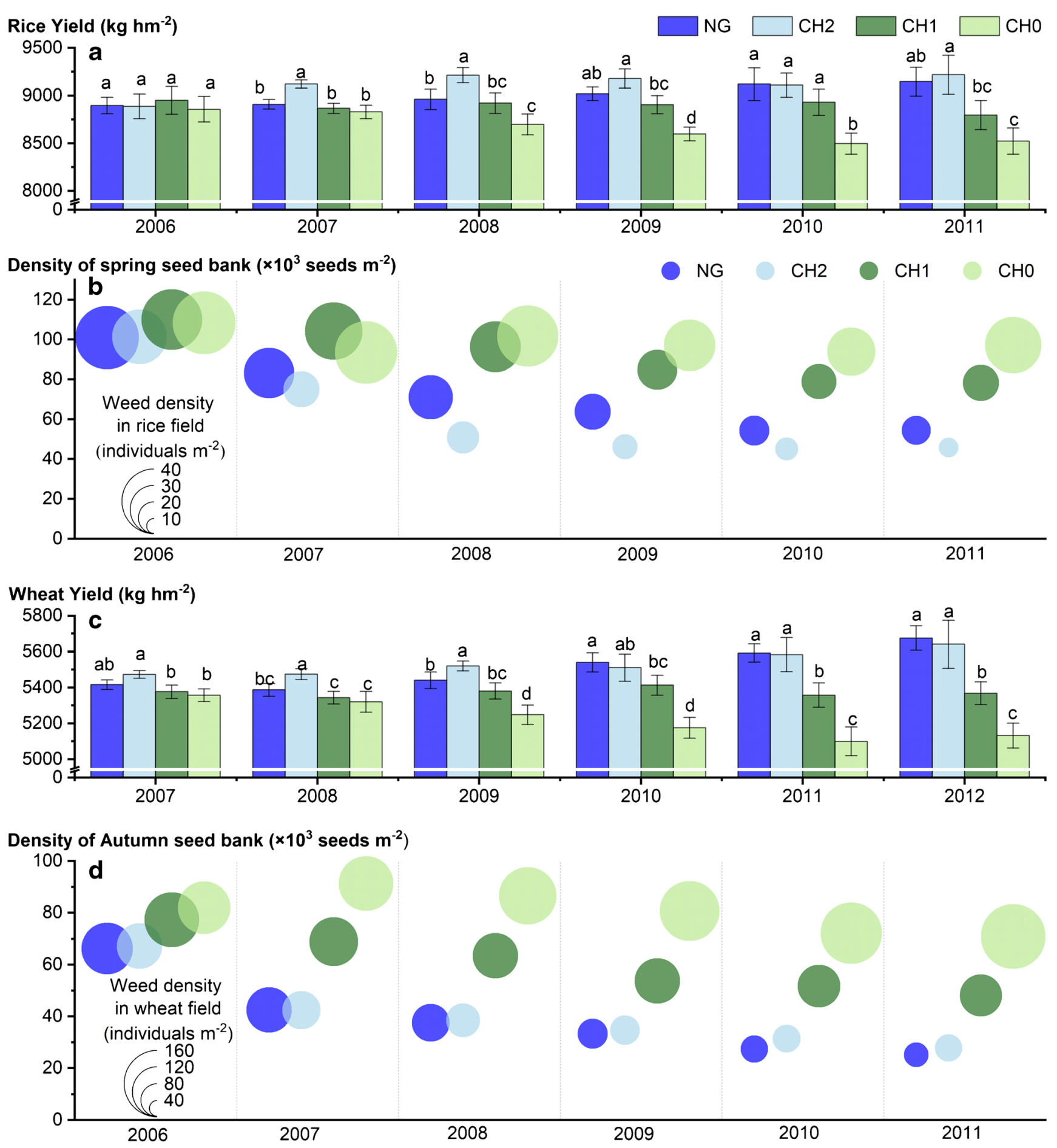

Fig. 5 Influence of management strategies on rice and wheat yields (a and c) and the corresponding weed population and the soil seed bank dynamics ( $b$ and $d$ ). The error bars indicate the means \pm SEs. The

\subsection{Quantitative analysis of $A$. japonicus}

\subsubsection{Seed bank input and output}

Seed banks can reach a dynamic equilibrium when the seed input and output rates are equal. An understanding of the different lowercase letters indicate significantly different densities at $\mathrm{p} \leq 0.05$ between treatments based on Fisher's least significant difference (F-LSD) tests. relationship between input/output and seed bank density could help management efforts. Parameter values were calculated according to the investigation data (Table 2). When the calculated parameter values are used, the predicted trends with the matrix model largely reflect the actual results. According to the matrix model, the input and output of the weed seed bank 
Table 2 Parameter values and the initial seed bank densities under different treatments. $g$ plant recruitment (seed germination rate), $\beta_{\mathrm{w}}$ seed survival rate from through November to July in seed bank, $\mu$ plant survival rate after the chemical herbicide used, $f$ seed production per plant (plant fecundity), $\eta$ proportion of seeds shattered onto soil surface prior to irrigation, $\alpha$ the depleting of newly shattered seeds during irrigation, $\beta_{\mathrm{s}}$ seed survival rate from July to October through in seed bank, $\sigma_{\mathrm{g}}$ and $\sigma_{\mathrm{f}}$ the density-dependent parameters

\begin{tabular}{|c|c|c|c|c|c|c|c|c|c|c|}
\hline \multirow[t]{2}{*}{ Treatment } & \multirow{2}{*}{$\begin{array}{l}\text { Seed bank density } \\
n_{\mathrm{t}}\end{array}$} & \multicolumn{9}{|c|}{ Parameter values } \\
\hline & & $g$ & $\beta_{\mathrm{w}}$ & $\mu$ & $f$ & $\eta$ & $\alpha$ & $\beta_{\mathrm{s}}$ & $\sigma_{\mathrm{g}}$ & $\sigma_{\mathrm{f}}$ \\
\hline NG & 21289 & 0.11 & 0.64 & 0.1 & 268 & 0.5 & 0.6 & 0.77 & 0.00005 & 0.00002 \\
\hline $\mathrm{CH} 2$ & 21067 & 0.11 & 0.64 & 0.075 & 268 & 0.5 & 0.28 & 0.77 & 0.00005 & 0.00002 \\
\hline $\mathrm{CHO}$ & 21467 & 0.11 & 0.64 & 0.1 & 268 & 0.5 & -0.1 & 0.77 & 0.00005 & 0.00002 \\
\hline $\mathrm{CH} 1$ & 20711 & 0.11 & 0.64 & 0.1 & 268 & 0.5 & 0.28 & 0.77 & 0.00005 & 0.00002 \\
\hline
\end{tabular}

for A. japonicus were calculated (Fig. 6b). Except under CH0 treatment, the input of the $A$. japonicus seed bank under the treatments was less than the output, but the gap between the seed bank input and output narrowed with increasing time under all four treatments, which indicated that the decline or increase in the seed bank size slowed and that the seed bank tended towards stability in the long term.

The seed input of the A. japonicus seed bank was the lowest under the NG treatment, which indicated that the removal of floating weed seeds via nets could effectively reduce the seed rain input. The seed input was the second-lowest under $\mathrm{CH} 2$ treatment, which could control the seed rain input by effectively controlling the weed population density. For $\mathrm{CH} 0$ treatment, the seed bank input was greater than its output, which would lead to an increase in the A. japonicus seed bank density.

The changes in the species composition of the weed seed bank in response to weed management strategies, together with the interaction of weed species within the weed community, were determined (Barberi et al. 1998; Mayor and Dessaint 1998). To determine strategic weed management activities, quantitative insight into the dynamics of weed populations is needed. This quantitative approach analysis of the dynamics of weed populations has high potential as a predictive tool for use in weed control advisory systems. With respect to specific weed species, the effect of a particular weed control measure can be explained clearly via quantitative analysis of the soil seed bank to predict the population dynamics.

In this study, quantitative analysis of A. japonicas was implemented using the matrix model. For the analysis, the seed production, seedling emergence rate, chemical control efficacy, seed interception, and floating seed capture efficiency of A. japonicas were evaluated. The results showed that, except under $\mathrm{CH} 0$ (traditional chemical weed control), the seed bank input was smaller than the output under the treatments (ecological weed control integrated with chemical weed control), resulting in a gradual decrease in its seed bank size each year (Fig. 6c). However, as the number of treatment years increased, the gap between the seed bank output and input diminished, which means that the seed bank will tend to stabilize.

By comparison, $\mathrm{CH} 2$ and $\mathrm{NG}$ were the most effective at controlling the weed species A. japonicas (Fig. 6d). Chemical weed control ( $\mathrm{CH} 2)$ was directly aimed at reducing the number of individual weeds before plant fructification to reduce seed rain, while removal of weed seeds with nets $(\mathrm{NG})$ was directly aimed at reducing seed rain input after plant fructification. Because of the high buoyancy of $A$. japonicas seeds, the newly shattered seeds of $A$. japonicas can float on the water surface easily during irrigation events, which could facilitate their removal via tuck nets. In comparison with the $\mathrm{CH} 2$ treatment, efficient depletion of the weed seed bank (NG) was a better method of weed control, which indicated that removal of weed seeds with nets was a practical weed control method for the control of weed species whose seeds are floatable seeds (e.g., A. japonicas). Therefore, the removal of weed seeds via nets together with a single chemical weed control application (NG) can be used as an effective weed management regime under such conditions, especially for grassy weed control.

In practice, the choice of weed control strategies that require additional chemical weed control, ecological weed control, or IWM practices is based on the weed population density. The population density of dominant grassy weed species such as A. japonicas and B. syzigachne in winter wheat fields can be considered an indication of the choice of weed control strategies. If the A. japonicas density is extremely high (more than 60 individuals $\mathrm{m}^{-2}$ ), two applications of chemical weed control would be more effective the following year, and ecological weed control should be added. After 3 years, the weed density would be controllable with chemicals together with the removal of floating weed seeds by nets. If the density of $A$. japonicas is between 40 and 60 individuals $\mathrm{m}^{-2}$, single chemical control applications together with removal of floating weed seeds by nets would be effective. If the weed density decreases further (less than 40 individuals $\mathrm{m}^{-2}$ ), ecological 


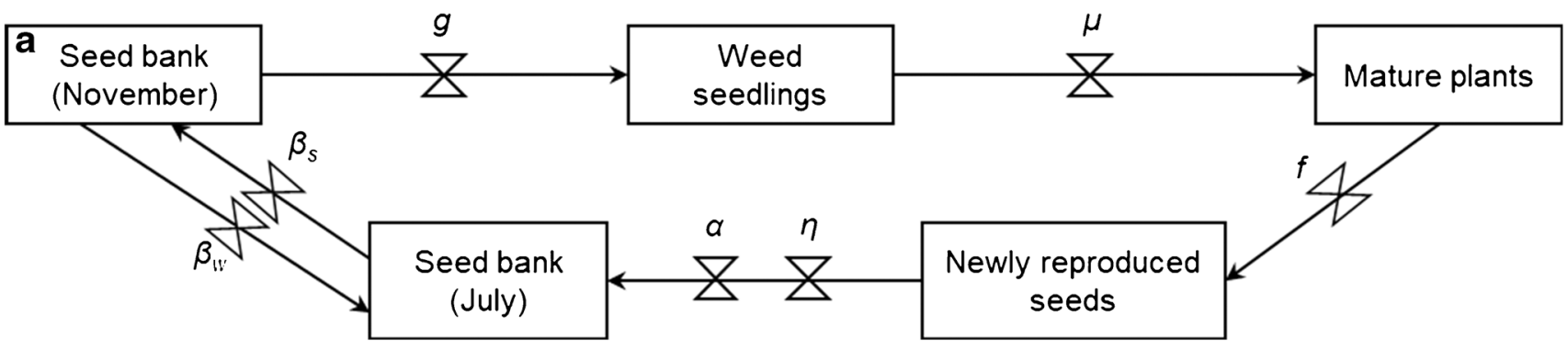

\section{Seed density (seeds $\mathbf{~ m}^{-2}$ )}

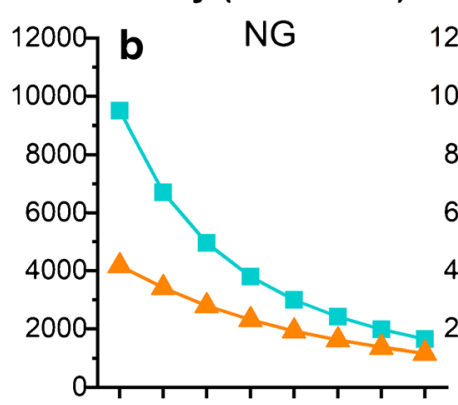

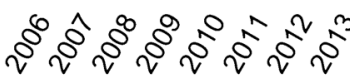

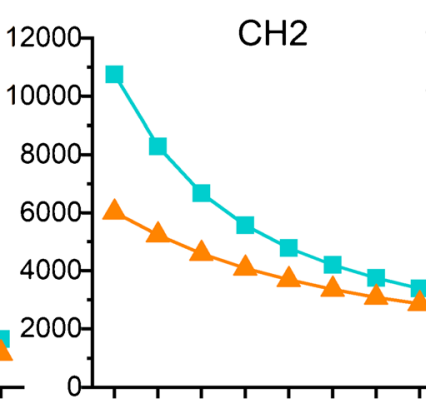

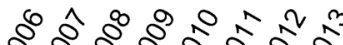

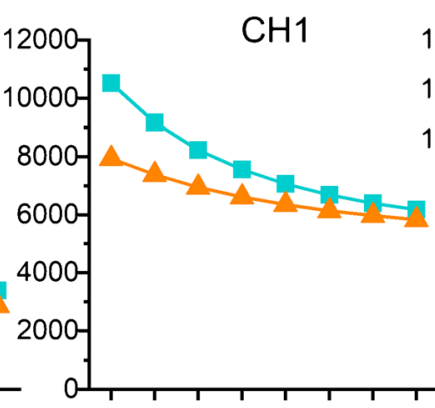

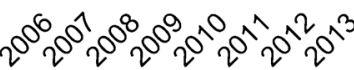

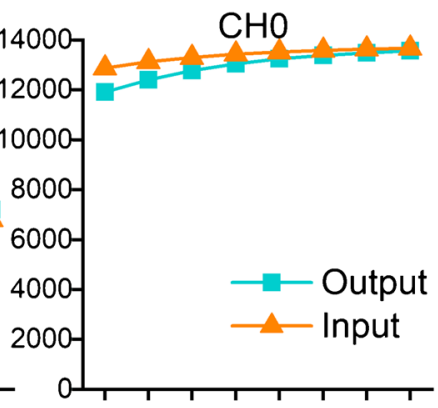

$8 \hat{0} \therefore 8 \leqslant \hat{s}$

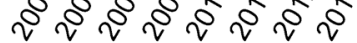

\section{Seed bank density (seeds $\mathrm{m}^{-2}$ )}

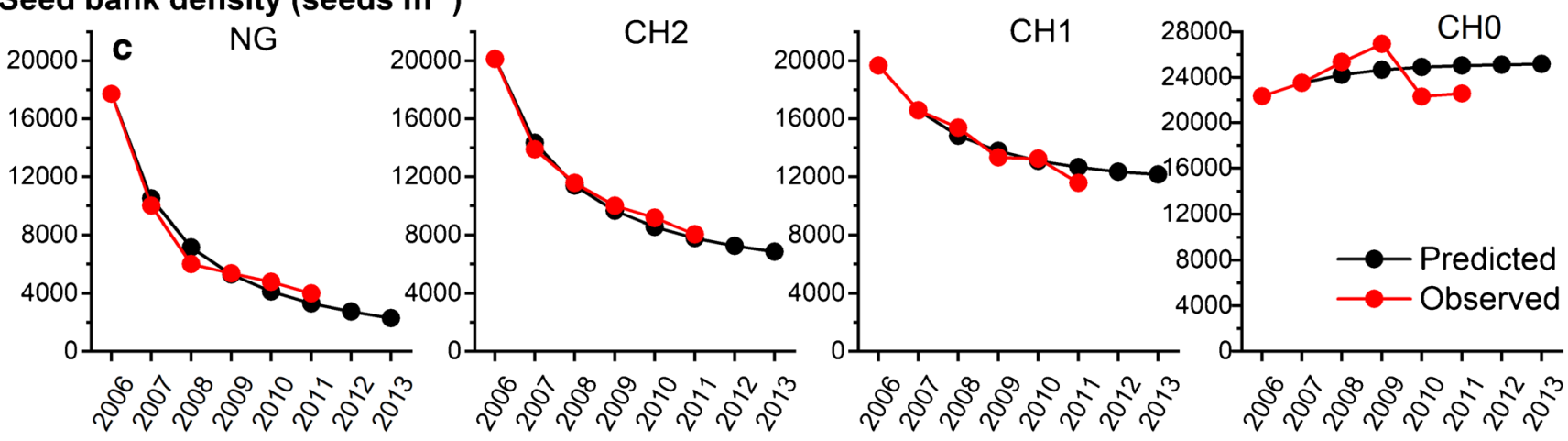

\section{Population density (individuals $\mathbf{~ m}^{-2}$ )}
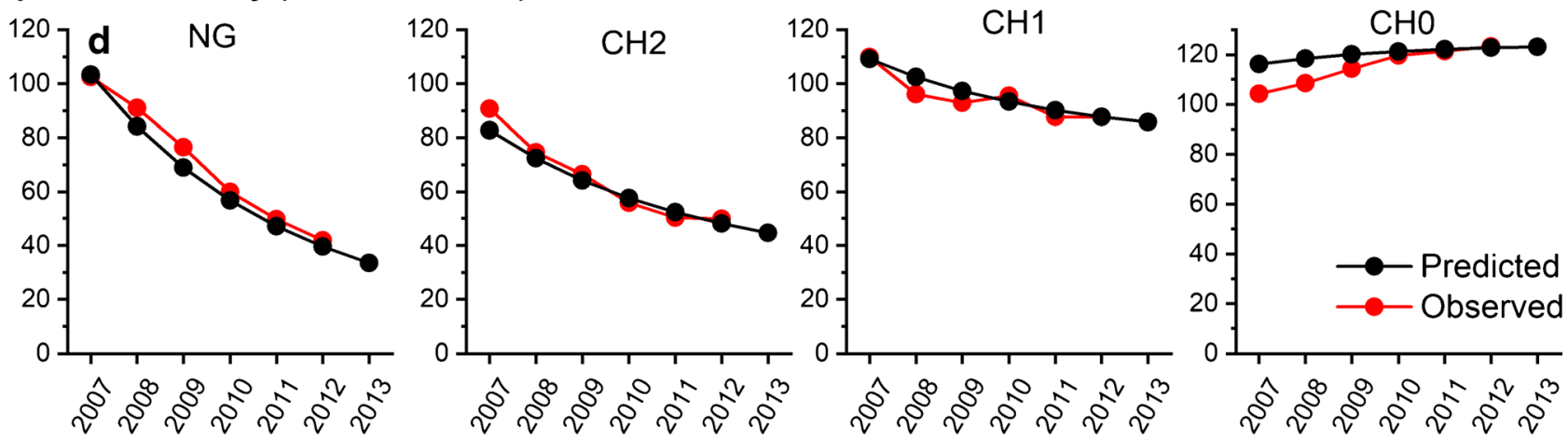

Fig. 6 Life cycle of Alopecurus japonicas (a), prediction of seed bank input and output of A. japonicus under four different treatments (b) and the predicted trend and observed dynamics of both the A. japonicas seed bank (c) and population density (d).

weed control alone could be enough to mitigate weed infestation, and the weed seed bank would be maintained at a small size.
The use of ecological measures that target the weed seed bank in the soil and minimize the size of the seed bank, such as the removal of weed seeds with nets, to control weeds may 
become more relevant in the future because of concerns about environmental pollution and because of sustainable agricultural development. Incorporating ecological measures as part of IWM strategies has great potential to reduce both herbicide applications and labor input. In general, the number of herbicide applications can be reduced by at least one (approximately $1000 \mathrm{~g} \mathrm{ha}^{-1}$ ) during the rice growing season each year, and the working time needed for weed control could be reduced by at least 30 hours $\mathrm{ha}^{-1}$. As a result, the cost of rice production would be greatly reduced, and food safety would be ensured.

\section{Conclusion}

This study, for the first time, developed two simple measures (seed interception and floating seed removal) to ecologically deplete the weed seed bank under a wheat-rice cropping system. Integrating the measures with conventional herbicide weed control could allow a reduction in the frequency of herbicide applications while sustainably reducing weed infestation levels. On the basis of the study results, we can conclude that a basic understanding of both seed bank dynamics and species composition allows farm managers to implement effective weed management practices that (1) optimize chemical weed control methods, (2) lower agrichemical use and input costs, (3) contribute to IWM, and (4) increase profits. Although the quantitative analysis results may be site specific and species specific, the general concept should be applicable to many other annual weed species and sites throughout ricewheat cropping systems.

Acknowledgments We are grateful to Prof. Bernal Eduardo Valverde from Investigación y Desarrollo en Agricultura Tropical, Costa Rica, and Prof. Stephen Powles from University of Western Australia for reviewing and valuable comments on the manuscript.

\section{Compliance with ethical standards}

Funding This research was financially supported by the National Key Research and Development Program of China (2016YFD0200805) and the China Transgenic Organism Research and Commercialization Project (2016ZX08011-001).

Conflicts of interest The authors declare that they have no conflicts of interest.

Author Contribution Conceptualization, S. Q; experiment performance, Z. Z, R. L, and C. Z; data analysis, Z. Z; writing of original draft, Z. Z; writing, reviewing, and editing, S. Q.

Data availability The datasets generated during and/or analyzed during the current study are available from the corresponding author on reasonable request.

\section{References}

Balasubramanian V, Ladha JK, Gupta RK, Naresh RK, Mehla RS, Singh B, Singh Y (2003) Technology options for rice in the rice-wheat system in South Asia. Improving the productivity and sustainability of rice-wheat systems: issues and impacts. 115-147

Baraibar B, Westerman PR, Carrión E, Recasens J (2009) Effects of tillage and irrigation in cereal fields on weed seed removal by seed predators. J Appl Ecol 46(2):380-387. https://doi.org/10.1111/j. 1365-2664.2009.01614.x

Barberi P, Cozzani A, Macchia M, Bonari E, Joanisse D, Michaud S, Inaguma Y, Tanguay R (1998) Size and composition of the weed seedbank under different management systems for continuous maize cropping. Weed Res 38(5):319-334. https://doi.org/10.1046/j.13653180.1998.00098.x

Bastiaans L, Paolini R, Baumann D (2008) Focus on ecological weed management: what is hindering adoption? Weed Res 48(6):481491. https://doi.org/10.1111/j.1365-3180.2008.00662.x

Buhler DD, Hartzler RG, Forcella F (1997) Implications of weed seedbank dynamics to weed management. Weed Sci 45(3):329 336. https://doi.org/10.1017/S0043174500092948

Chauhan BS, Johnson DE (2010) The role of seed ecology in improving weed management strategies in the tropics. Adv Agron 105(1):221262. https://doi.org/10.1016/S0065-2113(10)05006-6

Dauer JT, Mortensen DA, Vangessel MJ (2007) Temporal and spatial dynamics of long-distance Conyza canadensis seed dispersal. J Appl Ecol 44(1):105-114. https://doi.org/10.1111/j.1365-2664. 2006.01256.x

Davis AS, Dixon PM, Liebman M (2004) Using matrix models to determine cropping system effects on annual weed demography. Ecol Appl 14(3):655-668. https://doi.org/10.1890/02-5385

Fulekar H, Pathak B, Kale RK (2013) Soil seed bank dynamics: history and ecological significance in sustainability of different ecosystems. In: Environment and sustainable development. Springer, India, pp $31-46$

Guan GQ, Zhang YR, Sun GY, Ding SY, Wang YB (2000) Identification of weed seeds with color photos. Science Press, Beijing

Haring SC, Flessner ML (2018) Improving soil seed bank management. Pest Manag Sci 74(11):2412-2418. https://doi.org/10.1002/ps.5068

Hicks HL, Comont D, Coutts SR, Laura Crook L, Hull R, Norris K, Neve P, Childs DZ, Freckleton RP (2018) The factors driving evolved herbicide resistance at a national scale. Nat Ecol Evol 2:529-536. https://doi.org/10.1038/s41559-018-0470-1

Ladha J, Dawe D, Pathak H, Padre A, Yadav R, Singh B, Singh Y, Singh Y, Singh P, Kundu A (2003) How extensive are yield declines in long-term rice-wheat experiments in Asia? Field Crop Res 81(2): 159-180. https://doi.org/10.1016/S0378-4290(02)00219-8

Li R, Qiang S (2009) Composition of floating weed seeds in lowland rice fields in China and the effects of irrigation frequency and previous crops. Weed Res 49(4):417-427. https://doi.org/10.1111/j.13653180.2009.00709.x

Maclaren C, Storkey J, Menegat A, Metcalfe H, Dehnen-Schmutz K (2020) An ecological future for weed science to sustain crop production and the environment. A review. Agron Sustain Dev 40(4). https://doi.org/10.1007/s13593-020-00631-6

Mayor J-P, Dessaint F (1998) Influence of weed management strategies on soil seedbank diversity. Weed Res 38(2):95-105. https://doi.org/ 10.1046/j.1365-3180.1998.00075.x

Oerke E-C (2006) Crop losses to pests. J Agric Sci 144:31-43. https://doi. org/10.1017/S0021859605005708

Pywell RF, Heard MS, Woodcock BA, Hinsley S, Ridding L, Nowakowski M, Bullock JM (2015) Wildlife-friendly farming increases crop yield: evidence for ecological intensification. Proc R Soc B Biol Sci 282:20151740. https://doi.org/10.1098/rspb 
Qiang S (2002) Weed diversity of arable land in China. J Korean Weed Sci 22(3): 187-198

Qiang S (2005) Multivariate analysis, description, and ecological interpretation of weed vegetation in the summer crop fields of Anhui Province, China. J Integr Plant Biol 47(10):1193-1210. https://doi. org/10.1111/j.1744-7909.2005.00131.x

Rao AN, Brainard DC, Kumar V, Ladha JK, Johnson DE (2017) Preventive weed management in direct-seeded rice: targeting the weed seedbank. In: Advances in agronomy. Academic Press, Burlington, p 144:45-142

Reader R (1991) Control of seedling emergence by ground cover: a potential mechanism involving seed predation. Can J Bot 69(9):2084 2087. https://doi.org/10.1139/b91-260

Taylor KL, Hartzler RG (2000) Effect of seed bank augmentation on herbicide efficacy. Weed Technol 14(2):261-267. https://doi.org/ 10.1614/0890-037X(2000)014[0261:EOSBAO]2.0.CO;2

Timsina J, Connor D (2001) Productivity and management of rice-wheat cropping systems: issues and challenges. Field Crop Res 69(2):93132. https://doi.org/10.1016/S0378-4290(00)00143-X

Vasileiadis VP, Froud-Williams RJ, Eleftherohorinos IG (2007) Vertical distribution, size and composition of the weed seedbank under various tillage and herbicide treatments in a sequence of industrial crops. Weed Res 47(3):222-230. https://doi.org/10.1111/j.13653180.2007.00564.x
Webster TM, Cardina J, White AD (2003) Weed seed rain, soil seedbanks, and seedling recruitment in no-tillage crop rotations. Weed Sci 51(4):569-575. https://doi.org/10.1614/00431745(2003)051[0569:WSRSSA]2.0.CO;2

Westerman PR, Borza JK, Andjelkovic J, Liebman M, Danielson B (2008) Density-dependent predation of weed seeds in maize fields. J Appl Ecol 45(6):1612-1620. https://doi.org/10.1111/j.1365-2664. 2008.01481.x

Zhang ZP (2003) Development of chemical weed control and integrated weed management in China. Weed Biol Manag 3(4):197-203. https://doi.org/10.1046/j.1444-6162.2003.00105.x

Zhang Z, Li R, Wang D, Valverde BE, Qiang S (2019) Floating dynamics of Beckmannia syzigachne seed dispersal via irrigation water in a rice field. Agric Ecosyst Environ 277:36-43. https://doi.org/10. 1016/j.agee.2019.02.008

Zhu J, Wang J, DiTommaso A, Zhang C, Zheng G, Liang W, Islam F, Yang C, Chen X, Zhou W (2020) Weed research status, challenges, and opportunities in China. Crop Prot 134:104449. https://doi.org/ 10.1016/j.cropro.2018.02.001

Zuo R, Qiang S (2008) Species and dynamics of floating weed seeds in paddy field. Biodivers Sci 16:8-14. https://doi.org/10.1509/jimk.16. 3.108

Publisher's note Springer Nature remains neutral with regard to jurisdictional claims in published maps and institutional affiliations. 